\title{
Warthin's Tumour of the Parotid Glands, Adenomatous Hyperplasia and Oncocytic Adenomatous Hyperplasia of the Intranodal Heterotopic Salivary Glands: A Comparative Immunohistochemical Assessment
}

\author{
Masanori Shinohara, Seiji Nakamura, Takeshi Harada, Kazuto Yamada*, \\ Prashanta Shrestha* and Masahiko Mori* \\ Second Department of Oral and Maxillofacial Surgery, Faculty of Dentistry, Kyushu University, Fukuoka 812 and \\ ${ }^{*}$ Department of Oral and Maxillofacial Surgery, Asahi University School of Dentistry, Gifu 501-02
}

Received for publication November 2, 1995 and in revised form March 28, 1996

\begin{abstract}
Objectives: In adenomotous hyperplasia (AH) and oncocytic adenomatous hyperplasia (OAH) of the intranodal heterotopic salivary gland tissue and Warthin's tumours of the parotid glands, the expression of various intermediate filament proteins and other tissue markers in the epithelial components were compared, since they share common histopathological characteristics with both eosinophilic luminal cells and basal cells.

Materials and Methods: Tissue specimens from 79 intraparotid and extraparotid cervical lymph nodes containing heterotopic salivary gland tissue and 10 Warthin's tumours of parotid glands were evaluated for the expression of cytokeratins, vimentin, actin, epithelial membrane antigen (EMA), S-100 protein, lysozyme (Ly), lactoferrin (La), $\alpha 1$-antichymotrypsin ( $\alpha 1-A C T), \alpha 1$-antitrypsin ( $\alpha 1-A T)$, and human gastric and lung
\end{abstract}

cancer antigens by using the three stage streptavidin-biotin immunoperoxidase method.

Results and Conclusions: A similar profile of positive immunoreactivity for cytokeratins, EMA, Ly, La, a1-ACT, a1-AT and human lung and gastric cancer antigens was observed in the epithelial components of $A H, O A H$ and Warthin's tumours, while vimentin, actin and S-100 protein were negative in all of them. The histopathological and immunohistochemical profiles of $A H$ and $O A H$ in the intranodal heterotopic salivary gland tissue were closely mimicked by the epithelial tumour cells in Warthin's tumours. These findings suggest that Warthin's tumours may sometimes, but not always, arise from the ductal cells of heterotopic salivary gland tissue included in the lymph nodes.

Key words: Warthin's tumour, Lymph node, Intranodal salivary gland, Immunohistochemistry

\section{Introduction}

The major salivary glands, most commonly the parotid gland, contain lymphoid tissue in the form of either small intraglandular lymph nodes or accumulations of lymphoid cells [36]. Conversely, heterotopic salivary gland tissue (HSGT), which contains immature salivary glands with a potential for differentiation and proliferation, is frequently found in the intraparotid lymph nodes but rarely in the extraparotid cervical lymph nodes $[18,36$, 37]. The presence of a prominent lymphoid component in

Correspondence to: Dr. Masanori Shinohara, Second Department of Oral and Maxillofacial Surgery, Faculty of Dentistry, Kyushu University, 3-1-1 Maidashi, Higashi-ku, Fukuoka 812, Japan. some kinds of salivary gland diseases, such as lymphoepithelial lesions, lymphoepithelial cysts and Warthin's tumours, has been recognized [31], which thus indicates a close developmental association between lymphoid and salivary gland tissue.

Regarding the histogenesis of Warthin's tumours, they are thought to originate from the intranodal HSGT and involve either the intercalated ductal cells or other ductal cells $[1,7,10,11,29,33,34,36,37]$. Furthermore, Warthin's tumours have also been suggested to arise from ductal basal cells, since both tumour basal cells of Warthin's tumours and ductal basal cells in normal salivary glands show a similar profile of cytokeratin expression [3, $23,29,37]$. However, thus far few systematic investigations on intranodal HSGT have been carried out and, as a 
result, the histogenesis of Warthin's tumours remains obscure.

We previously reported that oncocytic metaplasia, adenomatous hyperplasia ( $\mathrm{AH})$ and oncocytic adenomatous hyperplasia (OAH) of HSGT in both the intraparotid and extraparotid lymph nodes are histomorphologically mimicked by the epithelial and lymphoid components of Warthin's tumours $[36,37]$. The present study was thus designed to evaluate the expression of various intermediate filament proteins and other tissue markers in intranodal HSGT and to elucidate to what extent such expression is similar to that seen in the epithelial component of Warthin's tumours.

\section{Materials and Methods}

A total of 79 lymph nodes (31 intraparotid and 48 extraparotid) containing HSGT were evaluated. These lymph nodes were obtained from 257 cases of neck dissection for oral malignant tumours and 35 cases of parotidectomy. The tumour specimens were obtained from 10 patients presenting with Warthin's tumours of the parotid gland. The specimens were routinely processed by fixation in $10 \%$ neutral buffered formalin, embedded in paraffin and then the sections were evaluated for their histopathological features using hematoxylin eosin staining as well as a PAS reaction.

For the immunohistochemical evaluation, serial sections at $4 \mu \mathrm{m}$ were examined using a three stage streptavidin immunoperoxidase technique along with 3,3'diaminobenzidine (DAB) hydrochloride in $0.05 \mathrm{M}$ Tris buffer solution containing $0.005 \%$ hydrogen peroxide at $\mathrm{pH} 7.6$ as a chromogen. The primary antibodies were all purchased commercially and their clones, dilutions and sources are listed in Table 1. Substitution by normal rabbit or mouse serum for each antibody was performed for the negative controls and salivary gland pleomorphic adenomas were used as the positive controls.

The immunostaining results were evaluated semi-quantitatively and classified as follows; $\mathrm{H}$ : strong expression, $H$ : moderate, + : slight, $+/-:$ traces, doubtfully detectable, 0 : not detectable.

\section{Results}

Immunohistochemical profile of normal salivary glands

In normal salivary glands (Fig. 1A), anti-cytokeratin antibody K8.12 showed a positive immunoreactivity in the intercalated, striated and excretory ducts with intense staining of the ductal basal cells (Fig. 1B). The ductal epithelium of the intercalated, striated and excretory ducts was also reactive with anti-cytokeratin antibody PKK1 (Fig. 1C). Anti-cytokeratin antibody KL1 showed a positive immunoreactivity on the lateral and basal borders of acinar cells, and a marked reaction in the intercalated, striated and excretory ducts (Fig. 1D). Epithelial membrane antigen (EMA) was positive on the luminal borders of the acini and ductal epithelium. Vimentin and S-100 protein were negative in the acini and ducts while actin was confined in the myoepithelial cells. Human lung cancer antigen detected by antibody KM-93 showed a positive immunoreactivity in the acini and intercalated ducts, but

Table 1. Primary antibodies for immunohistochemistry

\begin{tabular}{|c|c|c|}
\hline Antibody, type and specificity & Dilution & Source \\
\hline $\begin{array}{l}\text { Anti-cytokeratin } \mathrm{K} 8.12 \text {, mouse monoclonal IgG } \\
\text { to bovine epidermal keratin (no. } 3,16 \text { ) }\end{array}$ & $1: 20$ & Biomakor, Israel \\
\hline $\begin{array}{l}\text { Anti-cytokeratin PKK 1, mouse monoclonal IgG } \\
\text { to pig kidney epithelial cell line (no. } 8,18,19 \text { ) }\end{array}$ & $1: 40$ & Labsystem, Finland \\
\hline $\begin{array}{l}\text { Anti-cytokeratin KL } 1 \text {, mouse monoclonal IgG } \\
\text { to human epidermal Keratin (mol wt } 55-57 \mathrm{kDa} \text { ) }\end{array}$ & $1: 40$ & Immunoteck, France \\
\hline $\begin{array}{l}\text { Anti-EMA, mouse monoclonal IgG anti human } \\
\text { milk fat globule }\end{array}$ & $1: 20$ & Dakopatts, Denmark \\
\hline $\begin{array}{l}\text { Anti-Vimentin, mouse monoclonal IgG } \\
\text { to porcine eye lens }\end{array}$ & $1: 30$ & Dakopatts, Denmark \\
\hline Anti-Ly, rabbit polyclonal IgG to human & $1: 40$ & Dakopatts, Denmark \\
\hline Anti-La, rabbit polyclonal IgG to human & $1: 40$ & Dakopatts, Denmark \\
\hline Anti- $\alpha 1-\mathrm{ACT}$, rabbit polyclonal IgG to human & $1: 40$ & Dakopatts, Denmark \\
\hline Anti- $\alpha 1-\mathrm{AT}$, rabbit polyclonal IgG to human & $1: 40$ & Dakopatts, Denmark \\
\hline Anti-S-100P, rabbit polyclonal IgG to ox brain & $1: 100$ & Dakopatts, Denmark \\
\hline Anti-Actin, mouse monoclonal IgM to rabbit muscle & $1: 40$ & Dakopatts, Denmark \\
\hline $\begin{array}{l}\text { Anti-KM-93, mouse monoclonal IgG } \\
\text { to human lung cancer }\end{array}$ & $1: 40$ & Kyowa Medics, Japan \\
\hline $\begin{array}{l}\text { Anti-KM-231, mouse monoclonal IgG } \\
\text { to human gastric cancer }\end{array}$ & $1: 40$ & Kyowa Medics, Japan \\
\hline
\end{tabular}




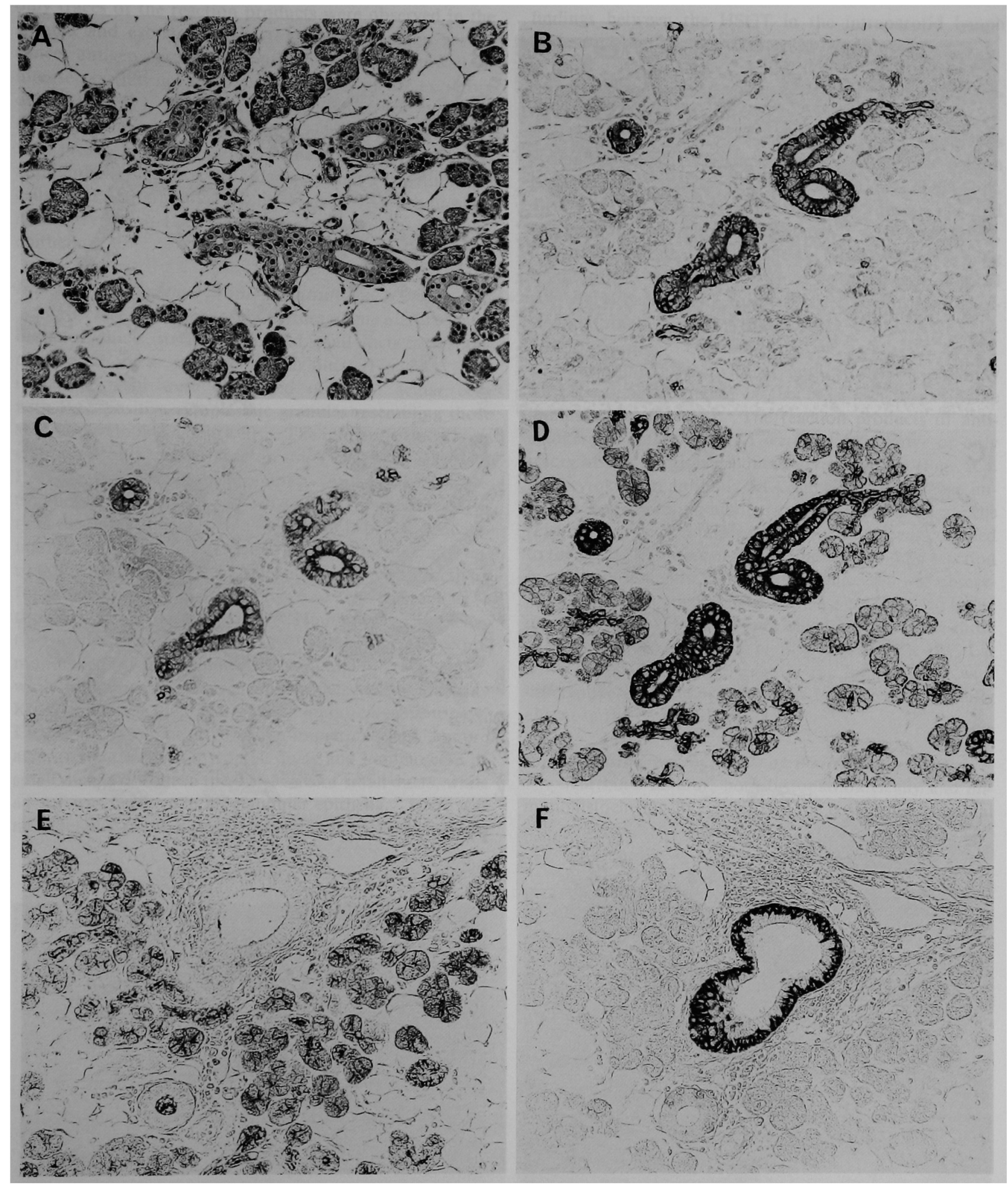

Fig. 1. Normal salivary gland tissue. $\times 180$. A: HE staining. Salivary gland tissue shows mature acini and ducts. B: Immunoreactivity of anti-cytokeratin antibody K8.12. The ductal basal cells of the mature ducts are positive. C: Immunoreactivity of anti-cytokeratin antibody PKK1. The luminal borders of the duct are positive. D: Immunoreactivity of anti-cytokeratin antibody KL1. The ducts and acini are positive. E: Human lung cancer antigen detected by antibody KM-93. The acini show moderate to strong staining, while the ducts are devoid of any staining. F: Human gastric cancer antigen detected by antibody KM-231. The basal cells of excretory ducts show strong staining, while the acini are devoid of any staining. 


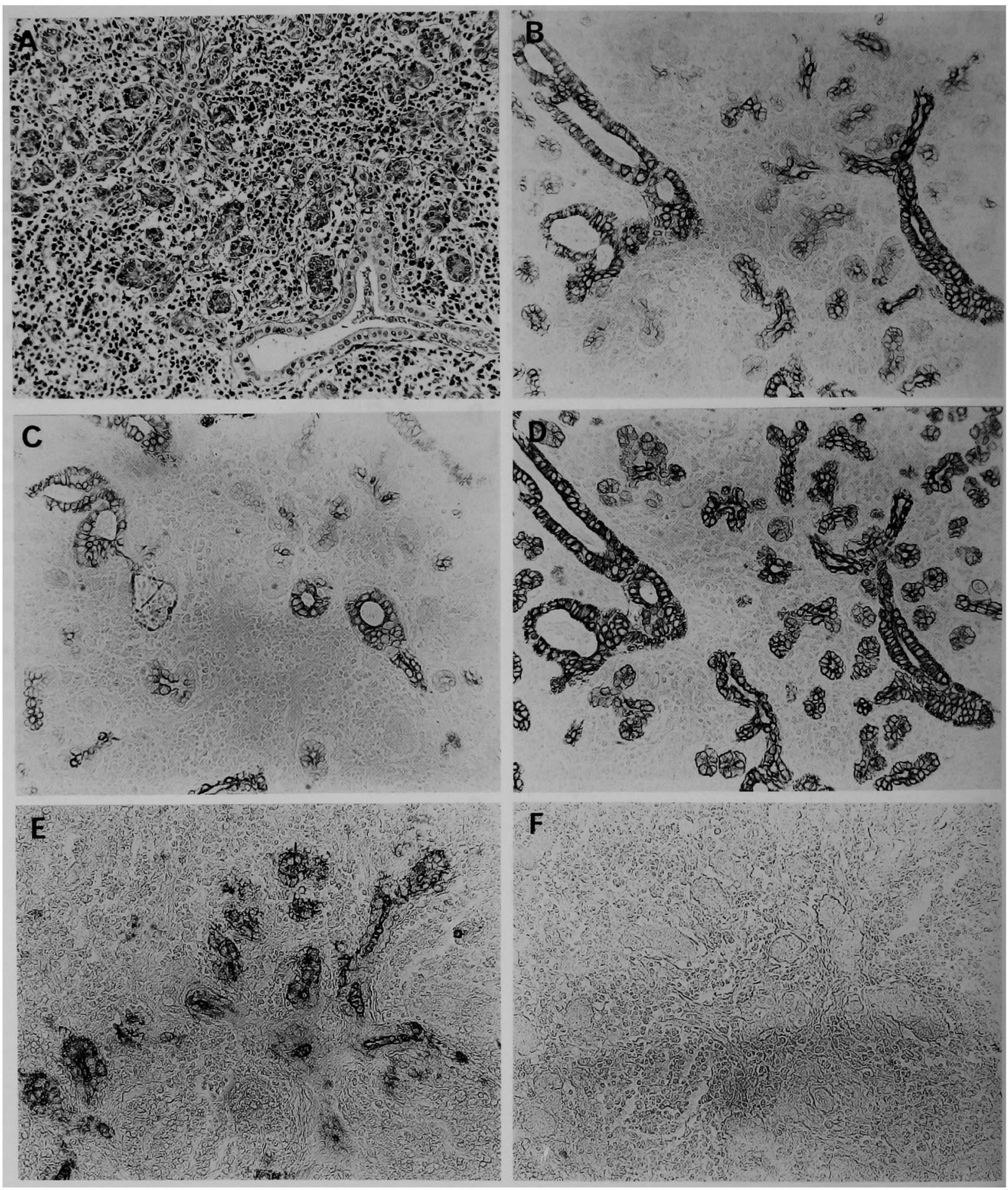

Fig. 2. HSGT in lymph node. $\times 180$. A: HE staining. Salivary gland tissue shows immature ducts and acini. B: Immunoreactivity of anti-cytokeratin antibody K8.12. The immature ducts and acini are positive. C: Immunoreactivity of anti-cytokeratin antibody PKK1. The immature ducts are positive. D: Immunoreactivity of anti-cytokeratin antibody KL1. The immature ducts and acini are positive. E: Human lung cancer antigen detected by antibody KM-93. The immature duct and acini show moderate to strong staining. F: Human gastric cancer antigen detected by antibody KM-231. The intranodal salivary gland tissue shows no staining. 
only traces of the reaction products were observed in the striated and excretory ducts (Fig. 1E). Human gastric cancer antigen detected by antibody KM-231 showed an intense reaction in the ductal basal cells of the excretory ducts (Fig. 1F). The immunoreactivities for lysozyme (Ly), lactoferrin (La) and $\alpha 1$-antichymotrypsin ( $\alpha 1$-ACT) were present in the acini, intercalated ducts, striated ducts and luminal cells of intralobular ducts but not in the basal cells of the interlobular duct. No reaction product for $\alpha 1$-antitrypsin ( $\alpha 1-\mathrm{AT})$ was observed in the glandular epithelium.

\section{Immunohistochemical profile of intranodal HSGT}

The HSGT comprised immature acini, mature acini, immature ducts, striated ducts and small ducts corresponding to the intra- and interlobular ducts (Fig. 2A). The immature acini were composed of small acinar cells with PAS-positive cytoplasmic granules resembling those seen in developing acinar cells. The immature ducts were composed of a single layer of small cuboidal cells with PAS-positive cytoplasmic granules. Anti-cytokeratin antibodies $\mathrm{K} 8.12$ and KL 1 showed a positive immunoreactivity in the immature ducts and acini (Fig. 2-B, D). The immature ducts were also reactive with anti-cytokeratin antibody PKK1 (Fig. 2C). The profile of immunoreactivity for EMA, vimentin, S-100 protein and actin was similar to that seen in the normal glands. Human lung cancer antigen detected by antibody KM-93 showed a positive immunoreactivity in the immature acini and ducts (Fig. 2E), while human gastric cancer antigen detected by antibody KM-231 did not (Fig. 2F). The immunoreactivity for Ly, La, $\alpha 1$-ACT was positive in the immature acini, mature acini, immature ducts, striated ducts and luminal cells of small ducts, but not in the basal cells of small ducts, while $\alpha 1$-AT was negative in all glandular epithelia. There was no difference in the histological and immunohistochemical

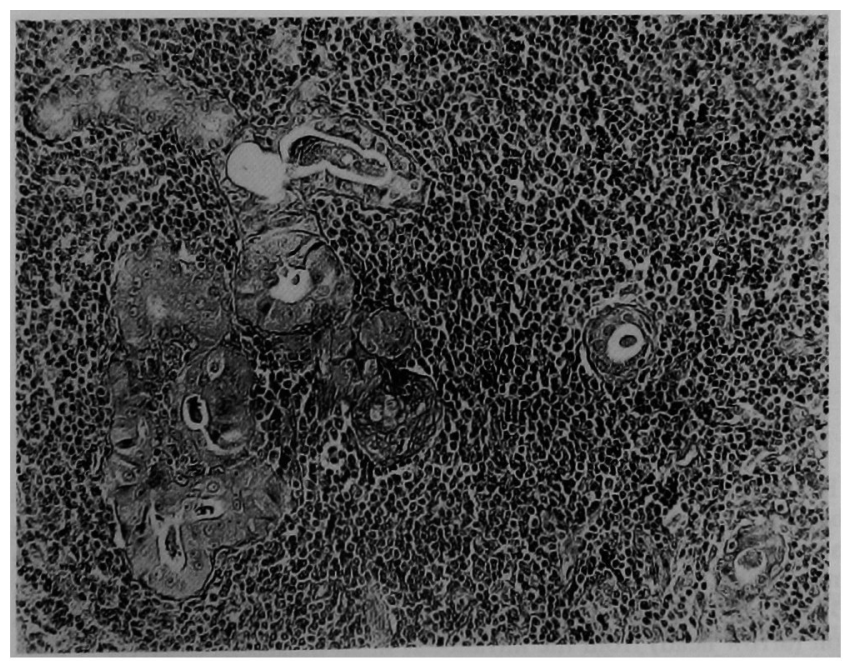

Fig. 3. AH of intranodal HSGT. $\times 180$. HE staining. The luminal cells and basal cells are shown. findings between the HSGT in the intraparotid lymph nodes and that in the extraparotid lymph nodes.

\section{Immunohistochemical profile of $\mathrm{AH}$ and $\mathrm{OHA}$ of intra- nodal HSGT}

In a total of the 79 intranodal HSGT specimens evaluated, oncocytic metaplasia was found in $10 \mathrm{lymph}$ nodes (12.7\%), AH (Fig. 3) in 2 (2.5\%), and OAH (Fig. 4 ) in $9(11.4 \%)$. OAH ranged from $3-7 \mathrm{~mm}$ in size and was continuous with small ducts. $\mathrm{AH}$ and $\mathrm{OAH}$, histopathologically, comprised two types of cells forming tubulo-ductal structures, luminal cells and non-luminal polyhedral basal cells. In most cases, a transition of intranodal small ducts to $\mathrm{AH}$ and $\mathrm{OAH}$ was observed (Fig. 5A).

The immunoreactivity of anti-cytokeratin antibody $\mathrm{K} 8.12$ was more intense in the basal cells than in the luminal cells (Fig. 5B). The reaction products of anticytokeratin antibody PKK1 were either negative or only traces of the reaction products were observed (Fig. 5C). Anti-cytokeratin antibody KL1 showed more intense immunoreactivity in the luminal cells than in the basal cells (Fig. 5D). The immunoreactivity for EMA was confined to the luminal borders of the luminal cells and no reaction product for vimentin, S-100 protein and actin was observed. The reaction products of KM-93 were observed in the luminal borders of the luminal cells (Fig. 5E) while those of KM-231 were seen in the basal cells (Fig. 5F). Ly, La, $\alpha 1$-ACT, $\alpha 1$-AT were present in the luminal cells with different reaction intensities, while they were consistently absent in the basal cells.

\section{Immunohistochemical profile of Warthin's tumours}

Warthin's tumour, both histopathologically and immunohistochemically, comprised the eosinophilic luminal

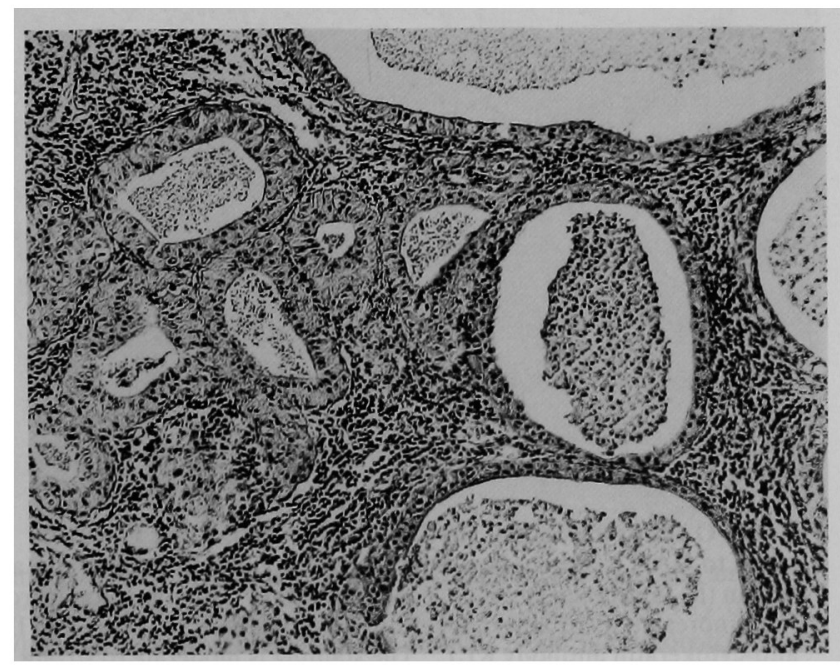

Fig. 4. OAH of intranodal HSGT. $\times 100$. HE staining. Two types of cells, eosinophilic luminal cells and polyhedral basal cells, are shown. 


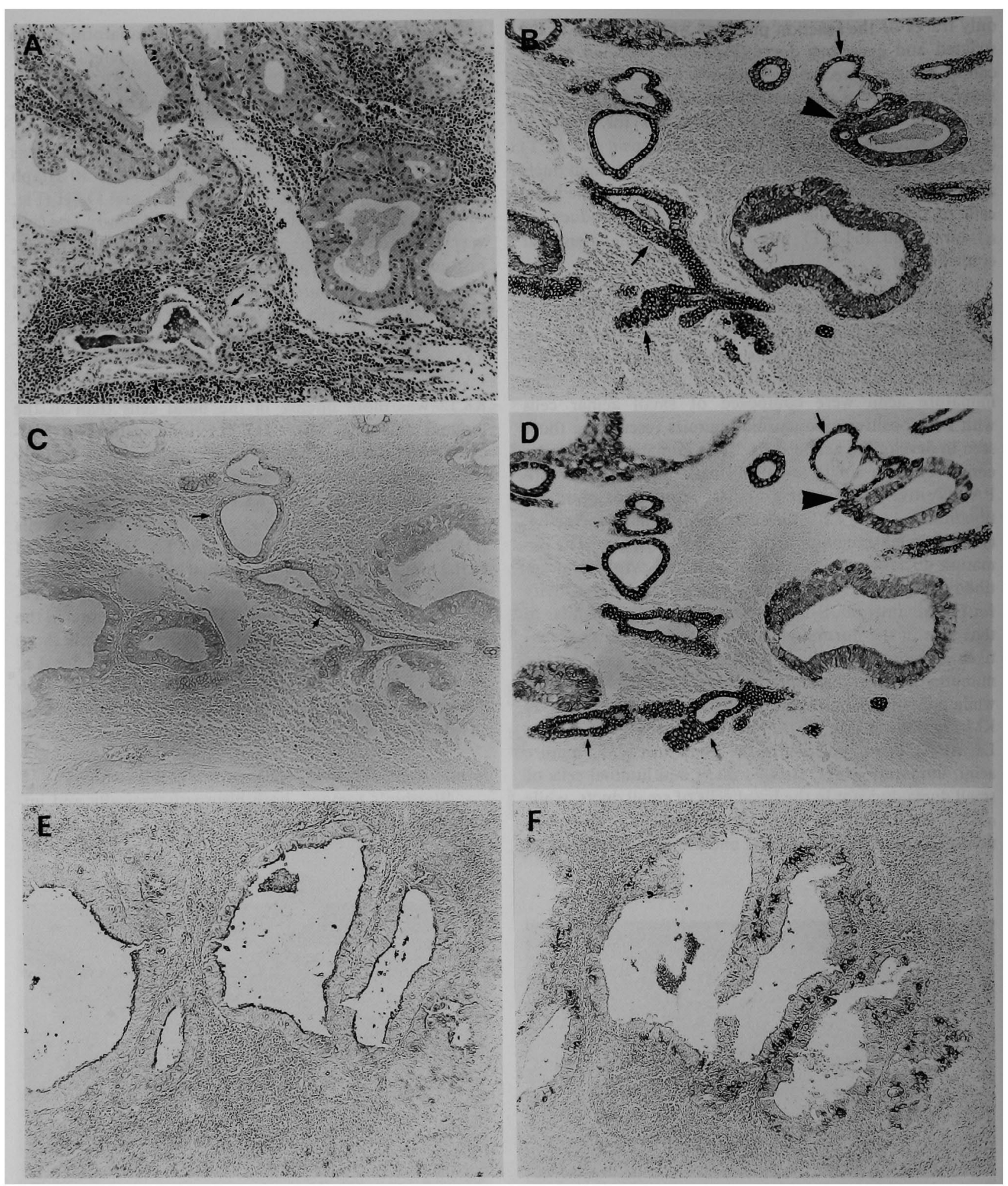

Fig. 5. OAH of intranodal HSGT. A-D $\times 100$. $\quad \mathbf{E} \& \mathbf{F} \times 210$. A: HE staining. The transition from the intranodal small duct cells (arrows) to $\mathrm{OAH}$ is seen. B: Immunoreactivity of anti-cytokeratin antibody K8.12. Moderate staining is seen in OAH, but it is weaker than that in the intranodal small duct cells (arrows). The transition (arrow head) from the intranodal small duct cells (arrow) to OAH is seen. C: Immunoreactivity of anti-cytokeratin antibody PKK1. OAH and the intranodal small duct cells show no staining. D: Immunoreactivity of anti-cytokeratin antibody KL1. The staining is moderate to strong in OAH and is stronger in the basal cells than in the luminal cells. The intranodal small duct cells (arrow) show strong staining and the transition (arrow head) from the intranodal small duct cells to OAH is seen. E: Human lung cancer antigen detected by antibody KM-93. The luminal cells show moderate staining only at the luminal borders, while the basal cells show no staining. F: Human gastric cancer antigen detected by antibody KM-231. The basal cells show moderate staining, while the luminal cells show no staining. 

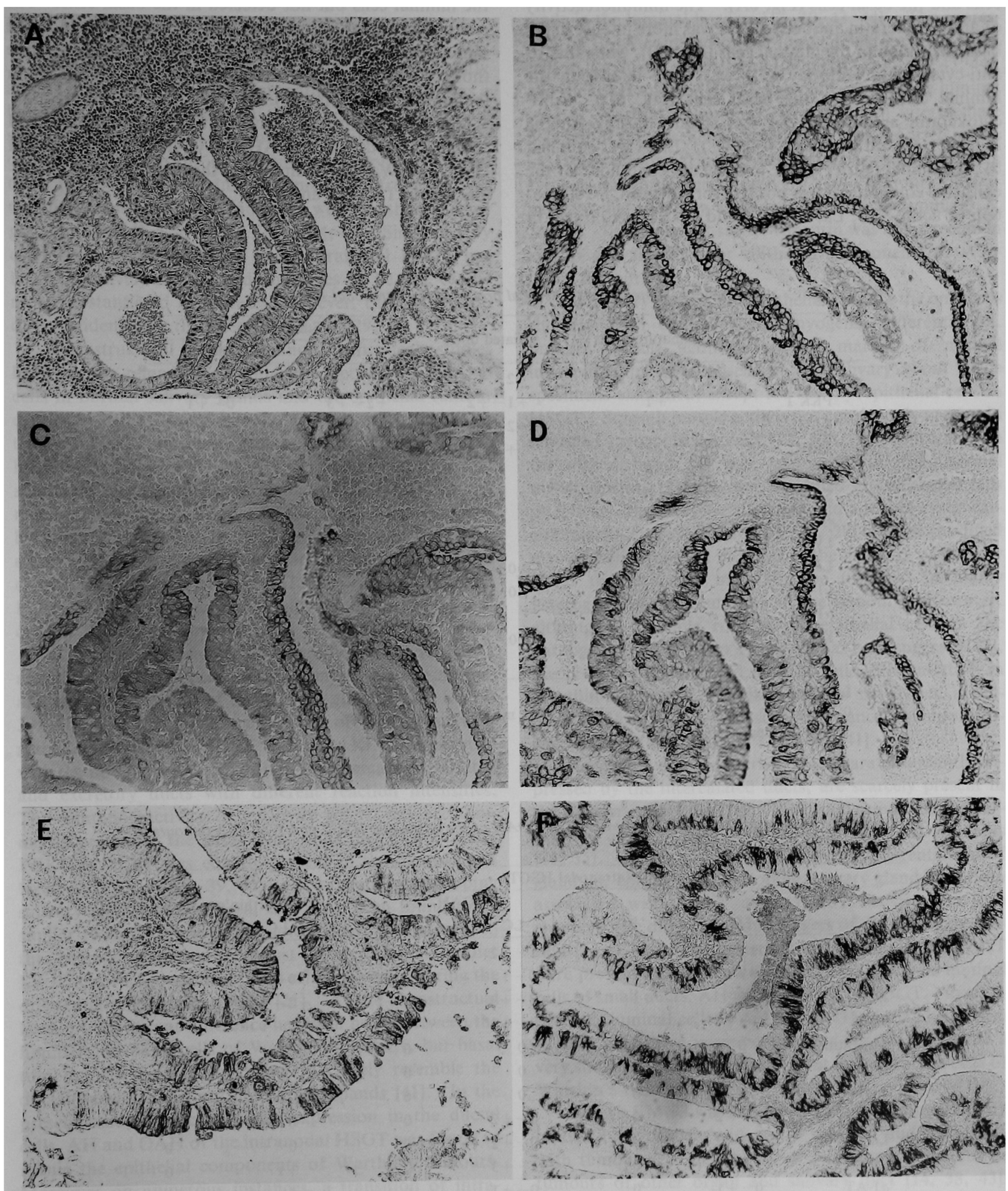

Fig. 6. A Warthin's tumour. A-D $\times 110 . \quad \mathbf{E} \& \mathbf{F} \times 140$. A: HE staining. Warthin's tumour shows eosinophilic luminal cells and basal cells. B: Immunoreactivity of anti-cytokeratin antibody K8.12. The basal cells show strong staining. C: Immunoreactivity of anticytokeratin antibody PKK1. The basal cells show moderate staining, while the luminal cells show slight staining. D: Immunoreactivity of anti-cytokeratin antibody KL1. The luminal and basal cells show moderate to strong staining. E: Human lung cancer antigen detected by antibody KM-93. The luminal cells show moderate staining, while the basal cells show no staining. F: Human gastric cancer antigen detected by antibody KM-231. The basal cells show moderate staining, while the luminal cells show no staining. 
cells and the basal cells (Fig. 6A). The immunoreactivity of anti-cytokeratin antibody $\mathrm{K} 8.12$ was more intense in the basal cells than in the luminal cells (Fig. 6B), while that of anti-cytokeratin antibody $\mathrm{KL} 1$ was more intense in the luminal cells than in the basal cells (Fig. 6D). Anticytokeratin antibody PKK1 was slightly reactive in the luminal cells and basal cells (Fig. 6C). EMA was confined to the luminal border of the luminal cells and none of the epithelial components was positive for vimentin, S-100 protein or actin. $\mathrm{Ly}, \mathrm{La}, \alpha 1-\mathrm{ACT}$ and $\alpha 1-\mathrm{AT}$ were traces in the luminal cells but not detected in the basal cells. The reaction products of antibody KM-93 were detected in the luminal cells but not in the basal cells (Fig. 6E), while those of antibody KM-231 were in the basal cells but not in the luminal cells (Fig. 6F).

A comparative assessment of immunohistochemical profile of the ductal cells $\mathrm{AH}$ and $\mathrm{OAH}$ of the intranodal HSGT and Warthin's tumours of the parotid glands is summarized in Tables 2 and 3.

Table 2. Immunohistochemical profile of the intranodal HSGT

\begin{tabular}{lcccc} 
& \multirow{2}{*}{ Immature ducts } & Striated ducts & \multicolumn{2}{c}{ Small duct } \\
\cline { 3 - 5 } & & & LC & BC \\
\hline K8.12 & $+1-+2$ & $+2-+3$ & $+2-+3$ & $+2-+3$ \\
PKK 1 & +1 & $+1-+2$ & $+2-+3$ & $0-+1$ \\
KL 1 & $+2-+3$ & $+2-+3$ & +3 & $0-+1$ \\
EMA & $+1^{*}$ & $+1^{*}$ & $+1^{*}$ & 0 \\
Vimentin & 0 & 0 & 0 & 0 \\
S-100P & 0 & 0 & 0 & 0 \\
Actin & 0 & 0 & 0 & 0 \\
Ly & $0-+1$ & 0 & 0 & 0 \\
La & +1 & $0-+1$ & $0-+1$ & 0 \\
$\alpha 1-$ ACT & $0-+1$ & $0-+1$ & $0-+1$ & 0 \\
$\alpha 1-$ AT & 0 & 0 & 0 & 0 \\
KM-93 & $+1-+2$ & $0-+1-$ & $0-+1-$ & 0 \\
KM-231 & 0 & 0 & 0 & 0 \\
\hline
\end{tabular}

LC: luminal cells, BC: basal cells

0 : negative, $+/-$ : trace, +1 : slight, +2 : moderate, +3 : strong

*: only luminal surface

Table 3. Immunohistochemical profile of AH and OAH of the intranodal HSGT and Warthin's tumours of the parotid glands

\begin{tabular}{lcccccc} 
& \multicolumn{4}{c}{ Intranodal HSGT } & \multicolumn{2}{c}{ Warthin's tumours } \\
\cline { 2 - 5 } & LC & AH & BC & LC & BC & \multicolumn{2}{c}{ LC } & BC \\
\hline K8.12 & +1 & $+1-+2$ & $+1-+2$ & $+2-+3$ & $+1-+2$ & $+2-+3$ \\
PKK 1 & $+1-$ & $0-+1-$ & $0-+1-$ & $0-+1-$ & $0-+2$ & $0-+1$ \\
KL 1 & +2 & +1 & $+2-+3$ & $+1-+2$ & $+2-+3$ & $+1-+2$ \\
EMA & $0-+1^{*}$ & 0 & $0-+1^{*}$ & 0 & $+/--+1^{*}$ & 0 \\
Vimentin & 0 & 0 & 0 & 0 & 0 & 0 \\
S-100P & 0 & 0 & 0 & 0 & 0 & 0 \\
Actin & 0 & 0 & 0 & 0 & 0 & 0 \\
Ly & $0-+2$ & 0 & $0-+2$ & 0 & $0-+1-$ & 0 \\
La & $0-+2$ & 0 & $0-+2$ & 0 & $0-+1-$ & 0 \\
$\alpha 1-A C T$ & $+1-+3$ & 0 & $+1-+3$ & 0 & +1 & 0 \\
$\alpha 1-A T$ & $0-+1$ & 0 & $0-+1$ & 0 & $0-+1-$ & 0 \\
KM-93 & +1 & 0 & +1 & 0 & $+1-+2$ & 0 \\
KM-231 & 0 & $+1-+3$ & 0 & $+1-+3$ & 0 & $+2-+3$ \\
\hline
\end{tabular}

LC: luminal cells, BC: basal cells

0 : negative, $+/-:$ trace, +1 : slight, +2 : moderate, +3 : strong

*: only luminal surface 


\section{Discussion}

Warthin's tumour, a benign neoplastic lesion mostly arising in the parotid gland, histopathologically contains a lymphoid matrix and epithelial tumour cells forming cystic spaces. Oncocytosis, squamous metaplasia and mucous cell metaplasia are the most common histological variations [34]. There remains widespread controversy over the histogenesis of this tumour, as well as other salivary gland tumours $[3-5,7,12,22,31,33,34,43]$. Since the very early days, its histogenesis from intranodal HSGT has been extensively studies and continues to be one of the most substantiated hypotheses, however, there is still no direct evidence for this theory $[1,2,11,29,36,37]$.

Ultrastructural and immunohistochemical studies have shown remarkable similarities between the ductal cells in normal salivary glands and the epithelial tumour cells of Warthin's tumour [41]. The characteristics of intranodal HSGT, however, remain largely unknown. The histomorphology of $\mathrm{AH}, \mathrm{OAH}$, ductal proliferation and squamous metaplasia, cyst formation and mucous cell metaplasia in the intranodal HSGT are closely mimicked by Warthin's tumours $[18,36,37]$. Therefore, the present study was designed to evaluate the immunohistochemical characteristics of ductal cells, $\mathrm{AH}$ and $\mathrm{OAH}$ of intranodal HSGT, and to compare them with the epithelial tumour cells of Warthin's tumours.

The cytokeratins detected by antibodies K8.12, PKK1 and KL1 have been consistently demonstrated in normal and neoplastic lesions of the salivary glands $[3,8,12,23$, $39,41]$. In the ductal epithelium of normal salivary glands, the antibodies $\mathrm{K} 8.12$, PKK1 and KL1 were reactive with the luminal and basal cells in the intercalated, striated and excretory ducts with different reaction intensities. The immunoreactivity of antibody K8.12 was predominantly present in the basal cells, while that of antibodies PKK1 and KL1 was equally present in the luminal and basal cells $[3,8,29,39,41]$. In prenatally developing salivary glands, ductal basal cells have been found to be similar to those found in the adult glands with respect to the expression of cytokeratins detected by antibodies K8.12 and PKK1 which appears relatively early during the differentiation of larger ducts [21]. At the ultrastructual level, no significant difference has been noted between the luminal and basal cells of Warthin's tumours, but basal tumour cells have been shown to closely resemble the ductal basal cells of normal parotid glands [41]. In the present study, the cytokeratin expression in the ductal cells, AH and OAH of the intranodal HSGT was found to mimic the epithelial components of Warthin's tumours. Moreover, in numerous instances, a transition of intranodal small ducts to $\mathrm{AH}$ and $\mathrm{OAH}$ was also observed. These results thus support the hypothesis that Warthin's tumours arise from the cells of the small ducts in intranodal HSGT.

The immunohistochemical detection of EMA in normal salivary glands and Warthin's tumours has been made in the luminal borders $[13,40,43,44]$. The expression of EMA confined to the luminal surface of luminal cells in the ductal epithelium of HSGT [13, 37, 40, 43, 44], and their $\mathrm{AH}$ and $\mathrm{OAH}$ was also mimicked by the luminal cells of Warthin's tumours. Vimentin, an intermediate filament of the mesenchymal cells, has been reported in few basal cells of normal salivary ducts and is coexpressed with cytokeratins in numerous salivary gland tumours such as pleomorphic adenoma and adenoid cystic carcinoma $[3,8$, $24,25]$. In the present study, vimentin was not detected in any of salivary ducts or epithelial components of Warthin's tumours.

In salivary glands, myoepithelial cells are the only cells showing both epithelial and myogenic differentiation. Smooth muscle actin, a specific marker of normal myoepithelium, was absent in the salivary gland tissue specimens examined, except for the myoepithelial cells in HSGT. Smooth muscle actin is not consistently present in modified myoepithelial cells $[17,30]$. S-100 protein, on the other hand, is not expressed in the normal myoepithelium [9], however, modified myoepithelial cells of salivary pleomorphic adenoma and adenoid cystic carcinoma do express $[6,16,23,24,28]$. Such modified myoepithelial cells are included in the majority of salivary gland tumours and may also be involved in highly heterogeneous differentiation of the tumours. However, although a possible role of myoepithelial cells in the pathogenesis of Warthin's tumours has been suggested [7], the present study showed no myogenic differentiation in Warthin's tumours. Similar findings have been anticipated following an ultrastructural and immunohistochemical study of Warthin's tumour [41].

Lysozyme and lactoferrin, which are abundantly expressed by the intercalated ducts, are scarcely present in the tumour epithelium [20]. In normal salivary tissue, $\alpha 1$ AT and $\alpha 1$-ACT have been reported in ductal segments $[21,35]$. Active proliferation and cytodifferentiation of glandular epithelia in developing salivary gland have been associated with $\alpha 1-\mathrm{AT}$ and $\alpha 1$-ACT activity and also characteristic differentiation markers of ductal differentiation [24, 27]. In the present study, Ly, La and $\alpha 1-\mathrm{ACT}$ were present in the immature ductal cells and the luminal cells of small ducts, $\mathrm{AH}$ and $\mathrm{OAH}$ of the HSGT. In addition, the luminal cells in AH and OAH of the HSGT also showed a positive immunoreactivity for $\alpha 1-\mathrm{AT}$, while a very similar distribution was present in the luminal cells of Warthin's tumours.

MoAb KM-93 was produced in mice immunized with human lung cancer, and reacts strongly and frequently with tumour cells of lung adenocarcinoma, a various of tumours of other organ and salivary duct [14, 38, 43]. The epitope of the antigen detected by MoAb KM-93 is a serine-, threonine-type carbohydrate chain sensitive to alkaline reduction. Immunologically, KM-93 recognize sialyl dimeric Lewis and sialyl antigen respectively, although some difference was noted [38, 43]. As regard MoAb KM-231, this was produced in mice immunized 
with human gastric cancer [15], and shows the strong immunohistochemical staining of glandular tumours. The immunohistochemical distribution of antigen detected by MoAb KM-231 somewhat resembles that of sialylated Lewis antigen [19]. The staining pattern of KM-93 recognized in acinar cell of normal salivary glands. In contrast, MoAb KM-231 stained with strong intensity the intercalated ducts, striated ducts and ductal basal cells located in the excretory duct [43]. In the present study, human lung cancer antigen was detected in the luminal cells of $\mathrm{AH}$ and OAH of the HSGT and Warthin's tumours, while the ductal basal cells of the salivary gland and Warthin's tumour were not staind with antibody KM-93. Conversely, human gastric cancer antigen was detected in the basal cells of AH and OAH of the HSGT as well as in the basal cells of Warthin's tumours. Similar findings have been anticipated following an immunohistochemical study of Warthin's tumour. The ductal basal cells of the salivary gland were strongly stained with antibody KM-231, while Warthin's tumour showed a positive KM-231 staining in the basal cells and a positive KM-93 staining in the luminal cells [43]. These findings thus suggest that the histogenesis of the basal cells in Warthin's tumours may possibly be from the ductal basal cells of HSGT through their $\mathrm{AH}$ and $\mathrm{OAH}$.

Previous studies have substantiated no role of autoimmune etiology in the pathogenesis of Warthin's tumours and have also suggested the possibility of Warthin's tumours arising from HSGT within the lymphoid stroma [11]. Our findings in the present study indicate that the expression of tissue markers in $\mathrm{AH}$ and $\mathrm{OAH}$ of intranodal HSGT is mimicked by the epithelial tumour cells of Warthin's tumours. Thus, Warthin's tumours may sometimes, but not always, arise from the ductal cells of intranodal HSGT through their AH and OAH. Furthermore, the incidence of HSGT is significantly higher in the intraparotid than in extraparotid lymph nodes [31, 34], although the incidence of oncocytic changes and $\mathrm{OAH}$ observed in the present study was not significantly different between these two groups of lymph nodes. If Warthin's tumours do arise from intranodal HSGT, then this would be consistent with the fact that the parotid gland is one of the most common occurring sites.

\section{Acknowledgments}

We thank Brian T. Quinn for reviewing the manuscript.

\section{References}

1. Batsakis, J. G. and Regezi, J. A.: The pathology of head and neck tumours salivary gland, part 1: Head Neck Surg. 1; 59-68, 1978.

2. Beck, L. D. and Maguda, T. A.: Papillary cystadenoma lymphomatosum (Warthin's tumour): A multicentric benign tumour. Laryngoscope 77; 1840-1848, 1967.
3. Born, I. A., Schweckheimer, K., Maiser, H. and Otto, H. F.: Cytokeratin expression in normal salivary glands and in cystadenolymphomas demonstrated by monoclonal antibodies against selective cytokeratin polypeptides. Virchows Arch. [A] 411; 583-589, 1987.

4. Caselitz, J. Osborn, M., Hamper, K., Wunstrow, J., Rauchfuss, A. and Weber, K.: Pleomorphic adenomas, adenoid cystic carcinomas and adenolymphomas of salivary glands analyzed by a monoclonal antibody against myoepithelial/ basal cells. An immunohistochemical study. Virchows Arch. [A] 409; 805-816, 1986a.

5. Caselitz, J., Walther, B., Wustrow, J., Seifert, G., Weber, K. and Osborn, M.: A monoclonal antibody that detects myoepithelial cells in exocrine glands, basal cell in other epithelia and basal suprabasal cells in certain hyperplastic tissues. Virchows Arch. [A] 409; 725-738, 1986b.

6. Croker, J., Jenkins, R., Campbell, J., Fuggle, W. J. and Shan, V. M.: Immunohistochemical demonstration of S-100 protein in salivary gland neoplasms. J. Pathol. 146; 115-121, 1985.

7. Cutler, L. S., Chaudhry, A. and Innes, D. J. Jr.: Ultrastructure of the parotid duct. Cytochemical studies of the striated duct and papillary cystadenoma lymphomatosum of the human parotid gland. Arch. Pathol. Lab. Med. 101; 420-424, 1977.

8. Dardick, I., Parks, W. R., Little, J. and Brown, D. L.: Characterization of cytoskeletal proteins in basal cells of human parotid salivary gland duct. Virchows Arch. [A] 412; 525-532, 1988.

9. Dardick, I., Strais, M., Parks, W. R., Debardi, F. G. and Kahn, H. J.: S-100 protein antibodies do not label normal salivary gland myoepithelium. Histologic implications for salivary gland tumours. Am. J. Pathol. 138; 619-628, 1991.

10. Eversole, L. R.: Histogenetic classification of salivary gland tumour. Arch. Pathol. Lab. Med. 92; 433-443, 1971.

11. Foulsham, C. K., Johnson, G. S., Synder, G. G., Carpenter, R. J. and Shafi, N. Q.: Immunohistopathology of papillary cystadenoma lymphomatosum (Warthin's tumour). Ann. Clin. Lab. Sci. 14; 47-63, 1984.

12. Geiger, S., Geiger, B., Leitener, O. and Marshak, G.: Cytokeratin polypeptides expression in different epithelial elements of human salivary glands. Virchows Arch. [A] 410; 403-414, 1987.

13. Gusterson, B. A., Lucas, R. B. and Ormerod, M. G.: Distribution of epithelial membrane antigen in benign and malignant lesions of salivary glands. Virchows Arch. [A] 397; 227-233, 1982.

14. Hanai, N., Shitara, K. and Yoshida, H.: Generation of monoclonal antibodies against human lung squamous cell carcinoma and adenocarcinoma using mice rendered tolerant to normal human lung. Cancer Res. 46; 4438-4443, 1986.

15. Hanai, N., Furuya, A., Shitara, K., Oda, S. and Yoshida, H.: Comparative studies on monoclonal antibodies raised against human gastric cancer for application to serum diagnosis of cancer. Anticancer Res. 8; 329-334, 1988.

16. Hara, K., Ito, M., Takeuchi, J., Iijima, S., Endo, T. and Hidaka, H.: Distribution of S-100b protein in normal salivary glands and salivary gland tumours. Virchows Arch. [A] 401; 237-249, 1983.

17. Hosaka, M., Takemoto, Y., Kawamura, K. and Mori, M.: Immunohistochemical evaluation of different filament protein in human salivary glands. Acta Histochem. Cytochem. 18; 504-514, 1985.

18. Iwata, Y., Matsuno, Y., Kawamura, K., Kurihara, K. and Hashimoto, N.: A histological study of the lymph nodes in the human parotid glands with special reference to the histogenesis of Warthin's tumour. J. Jpn. Saliva. Gland. Soc. 16; 22-24, 1974. 
19. Kannagi, R., Nudelman, E., Levery, S. B. and Hakomori, S.: A series of human erythrocyte glycosphingolipids reacting to the monoclonal antibody directed to a developmentally regulated antigen, SSEA-1. J. Biol. Chem. 257; 14865-14874, 1982.

20. Korsrud, F. R. and Brandtazaeg, P.: Charactelization of epithelial elemants in human major salivary glands by functional markers: Localization of amylase, lactoferrin, lysozyme, secretary component and secretary immunoglobulins by paired immunofluoresence staining. J. Histochem. Cytochem. 30; 657-668, 1984.

21. Lee, S. K., Lim, C. Y., Chi, J. G., Yamada, K., Hashimura, K., Kunikata, M. and Mori, M.: Prenatal development of human major salivary glands and immunohistochemical detection of Keratins using monoclonal antibodies. Acta Histochem. 89; 213-235, 1990.

22. Marshak, G. and Litner, O.: Cytokeratin polypeptides in normal and metaplastic human salivary gland epithelia. J. Oral Pathol. Med. 16; 442-449, 1987.

23. Mori, M., Ninomiya, T., Okada, Y. and Tsukitani, K.: Myoepitheliomas and myoepithelial adenomas of salivary gland origin. Immunohistochemical evaluation of filament proteins, S-100 alpha and beta, glial fibrillary acidic proteins, neuronspecific enolase and lactoferrin. Pathol. Res. Prac. 184; 168178, 1989.

24. Mori, M., Yamada, K., Tanaka, T. and Okada, Y.: Multiple expression of keratins, vimentin and S-100 protein in pleomorphic salivary adenomas. Virchows Arch. [B] 58; 435-444, 1990.

25. Morinaga, S., Nakajima, T. and Shimosato, Y.: Normal and neoplastic myoepithelial cells in salivary glands: An immunohistochemical study. Human Pathol. 18; 1218-1226, 1987.

26. Motoi, M., Stein, H. and Lennert, K.: Demonstration of lysozyme, alphal-antichymotripsin, alpha1-antitripsin, alubumin, and transferrin with the immunoperoxidase method in lymph node cells. Virchows Arch. [B] 35; 73-82, 1980.

27. Murase, N., Kobayashi, K., Mitani, H. and Mori, M.: Immunohistochemical localization of alphal antitripsin and alphal antichymotripsin in salivary pleomorphic adenomas. Virchows Arch. [A] 408; 107-116, 1985.

28. Noda, Y., Horiike, H., Tanimura, T., Tsujimura, T. and Mori, M.: Immunohistochemical localization by monoclonal antibodies of S-100 alpha and beta protein in mixed tumours and adenomas of the skin. Virchows Arch. [B] 54; 371-380, 1988.

29. Orito, T., Shinohara, H., Okada, Y. and Mori, M.: Heterogeneity of keratin expression in epithelial tumour cells of adenolymphoma in paraffin sections. Pathol. Res Pract. 184; 600-608, 1989.

30. Palmer, R. M., Eveson, J. W. and Gusterson, B. A.: Epimyoepithelial islands in lymphoepithelial lesions; An immunohistochemical study. Virchows Arch. [A] 408; 603-609, 1986.

31. Seifert, G.: World Health Organization International
Histological Classification of Tumours - Histological typing of salivary gland tumours. Springer Verlag, 1991.

32. Seifert, G. and Schultz, C.P.: Das monomorphe Speichelgangadenom. Klassifikation und Analyse von 79 Falen. Virchows Arch. [A] 383; 77-79, 1977.

33. Seifert, G:, Bull, H. G. and Donath, K.: Histologic subclassification of the cystadenolymphoma of the parotid gland. Analysis of 275 cases. Virchows Arch. [A] 388; 13-38, 1980.

34. Seifert, G., Miehlke, A., Haubrich, J. and Chilla, R.: Speicheldrusenkrankheiten. Pathologie Klinik Therapie Fazialischirurgie, Thieme Verlag, Stuttgart, New York, 1984.

35. Shested, M., Barfoed, C., Drogadhl, A. and Bretlau, P.: Immunohistochemical investigation of lysozyme, lactoferrin, alpha1-antitrypsin, alphal-antichymotripsin and ferritin in parotid gland tumours. J. Oral Pathol. 13; 524-534, 1984.

36. Shinohara, M., Harada, T., Nakamura, S., Oka, M. and Tashiro, H.: Heterotopic salivary gland tissue in lymph nodes of the cervical region. Int. J. Oral Maxilofac Surg. 21; 166171, 1992.

37. Shinohara, M., Harada, T., Oka, M., Yamada, K., Shrestha, P., Isono, K. and Mori, M.: Heterotopic salivary gland tissue in lymph nodes of head and neck : An immunohistochemical study. Acta Histochem. Cytochem. 22; 579-589, 1991.

38. Shitara, K., Hanai, N. and Yoshida, H.: Distribution of lung adenocarcinoma-associated antigens in human tissues and sera defined by monoclanal antibodies KM-52 and KM-93. Cancer Res. 47; 1267-1272, 1987.

39. Takai, Y., Yamada, K., Shinohara, H., Orito, T. and Mori, M.: Monoclonal antibodies against keratins bind to intercalated duct and ductal basal cells of normal salivary gland in paraffin sections. Acta Histochem. Cytochem. 21; 575-584, 1990.

40. Takemoto, Y., Kumasa, S., Watanabe, Y. and Mori, M.: Immunohistochemical expression of monoclonal antibody against epithelial membrane antigen in salivary gland tumour. Acta Histochem. Cytochem. 20; 113-124, 1987.

41. Tanaka, N., Hseih, K. J., Shioda, S., Miyamoto, H., Shinohara, H., Yamada, K., Yuba, R. and Mori, M.: Immunohistochemical and electron microscopic studies on epithelial tumour cells of cystadenolymphomas. Acta Histochem. Cytochem. 24; 181-189, 1991.

42. Toto, P. D. and Shu, D. J.: Product definition in case of myoepithelioma. Oral Surg. 62; 169-174, 1986.

43. Tsuji, T., Shinozaki, F., Yamada, K. and Mori, M.: Immunohistochemical detection of human lung and gastric cancer antigen in human salivary gland tumours. Anticancer Res. 9; 327-340, 1989.

44. Yamada, K., Tanaka, T., Mori, M., Tsubura, A., Morii, S., Tsubone, M., Ando, C. and Hilgers, J.: Immunohistochemical expression of MAM-3 and MAM-6 antigens in salivary tumours. Virchows Arch. [A] 415; 509-521, 1989. 